\title{
Protrombina mutante em indivíduos sob investigação de trombofilia
}

\author{
Mutant prothrombin in individuals under thrombophilia investigation \\ Catarina Paula da Silva Ramos'; Júlia Furtado Campos²; Maria Emília dos Santos³; Fárida Coeli de Barros Correia Melo \\ Washington Batista das Neves ${ }^{5}$; Fátima Alves Araújo ; Raul Antônio Morais Melo ${ }^{7}$
}

\begin{abstract}
unitermos
Trombofilia

Protrombina

Trombose venosa

\section{resumo}

Introdução: A doença tromboembólica é bastante freqüente, com incidência anual na população de 1 caso por mil indivíduos. Os fatores de risco para trombose incluem condições hereditárias e adquiridas. Uma mutação de ponto no fator II da coagulação, a protrombina G20210A (PTCR), constitui o segundo defeito genético mais comum associado à predisposição para trombose ou trombofilia. No Brasil, o estudo desse fator de risco é relativamente recente e se dispõe de poucos dados na literatura especializada. Objetivo: Este trabalho teve como objetivo determinar a freqüência da PTCR em 285 indivíduos sob investigação de trombofilia na Fundação de Hematologia e Hemoterapia de Pernambuco (HEMOPE/ PE). Material e método: A técnica molecular utilizada foi a enzima de restrição/reação em cadeia da polimerase (RE/PCR), com primers específicos e a enzima Hind III. Resultados: A freqüência encontrada da PTCR foi de $6 \%$ em heterozigose. A presença da mutação foi semelhante em indivíduos com idades tanto inferiores quanto superiores a 45 anos. Discussão: A presença da PTCR pode ter sido determinante para o surgimento dos quadros trombóticos, e a baixa mediana de idade do grupo estudado sugere que outras causas genéticas de trombofilia devem ser investigadas, pois a maioria dos trabalhos associa a presença de fator de risco genético a eventos trombóticos em indivíduos com idade inferior a 45 anos. Conclusões: Os resultados da pesquisa mostraram que a freqüência da PTCR na população estudada é semelhante à descrita na literatura científica para indivíduos selecionados com tromboembolismo e confirmam a importância do estudo molecular em diferentes faixas etárias.
\end{abstract}

Background: Thromboembolic disease is very common, with a yearly incidence in the general population of approximately 1 case per a thousand individuals. The risk factors for thrombosis include both hereditary and acquired conditions. A point mutation in coagulation factor II, prothrombin G20210A (PTCR), constitutes the second most prevalent genetic defect associated with the predisposition to thrombosis or thrombophilia. In Brazil, the study of this risk factor is relatively recent and there is little available data in medical literature. Objective: The aim of this study was to determine the frequency of PTCR in 285 individuals being investigated for thrombophilia at Fundação de Hematologia e Hemoterapia de Pernambuco (HEMOPE/PE). Material and method: The molecular biology technique used was restriction enzyme/polymerase chain reaction (RE/PCR), using specific primers and the Hind III enzyme. Results: The frequency of PTCR was 6\% in heterozygosis. The presence of the mutation was similar among individuals under and over 45 years old. Discussion: The presence of PTCR may have been a relevant factor for the episodes of thrombosis, and the low median age of the group suggests that other genetic causes of thrombophilia must be investigated inasmuch as most publications associate the presence of genetic risk factor with thrombotic events in individuals under 45 years old. Conclusions: Our findings showed that the frequency of PTCR in the studied population is similar to the results published in medical literature for selected patients with thromboembolism and they confirm the importance of molecular testing at different age groups. key words

Thrombophilia

Prothrombin

Venous thrombosis

1. Graduada em Ciências Biológicas; especialista em Análises Clínicas; mestranda em Cenética.

2. Craduada em Ciências Biológicas; especializanda em Biologia Molecular.

3. Craduada em Ciências Biomédicas; mestre em Bioquímica.

4. Craduada em Ciências Farmacêuticas; especialista em Biologia Molecular; mestranda em Energia Nuclear.

5. Graduado em Química; especialista em Tecnologia Ambiental.

6. Graduada em Medicina; especialista em Hematologia e Hemoterapia.

7. Graduado em Medicina; mestre em Doenças Infecciosas; doutor em Clínica Médica.

Trabalho realizado na Fundação de Hematologia e Hemoterapia de Pernambuco (HEMOPE/PE) - Unidade de Laboratórios Especializados/Laboratório de Biologia Molecular. 


\section{Introdução}

As doenças trombembólicas constituem um problema de saúde mundial por serem uma das causas mais comuns de morbidade, incapacitação e mortalidade, com incidência na população geral de um caso para cada 1.000 indivíduos/ ano ${ }^{(11,13)}$. Múltiplas interações entre fatores ambientais e genéticos contribuem para o desenvolvimento do trombembolismo ${ }^{(3)}$. Uma mutação de ponto no fator II da coagulação, a protrombina G20210A (PTCR), constitui após o fator $V$ de Leiden, o defeito genético mais comum associado à predisposição para trombose ou trombofilia ${ }^{(1,3,15)}$.

A protrombina sintetizada no fígado, na presença de vitamina K, é a precursora da trombina, que ao final da cascata da coagulação induz a formação da fibrina. Ademais, ela participa da regulação da coagulação, pois ao se ligar à trombomodulina ativa o sistema da proteína $C$, que tem papel crucial no equilíbrio pró-coagulante e/ou anticoagulante ${ }^{(13)}$.

O gene do fator II está localizado no cromossomo 11 próximo ao centrômero, contém aproximadamente 21.000 pares de bases $(\mathrm{pb})$ e é composto de 14 éxons e 13 íntrons ${ }^{(19)}$. Em 1996 foi descrita a variante alélica protrombina G20210A, uma mutação na região 3' não traduzida do gene da protrombina, que consiste na substituição de guanina por adenina no nucleotídeo 20210 localizada próximo ao sítio de clivagem do precursor do RNA mensageiro (RNAm) em que a cauda poli-A é adicionada. Essa mutação se associa a aumento da estabilidade do seu RNAm e concentração plasmática da protrombina, o que parece ser o mecanismo pelo qual predispõe à ocorrência de trombose ${ }^{(13)}$.

O diagnóstico laboratorial dessa alteração ocorre apenas por meio dos métodos de biologia molecular. Não é possível a investigação pelos níveis de protrombina, visto que há grande sobreposição entre os valores normais e aqueles dos portadores da mutação(6, 13).

Essa mutação ainda não foi encontrada em pacientes negros ou asiáticos ${ }^{(1,17,19)}$, mas está presente em cerca de $1 \%$ a $3 \%$ dos caucasóides ${ }^{(17,19)}$, com risco relativo para trombose de cerca de 2,8 vezes $(5,8,19)$.

No Brasil, o estudo desse fator de risco é relativamente recente e se dispõe de poucos dados na literatura especializada. A freqüência encontrada para a protrombina G20210A foi de $6,2 \%$ em pacientes com trombose venosa profunda ${ }^{(1)}$.

\section{Objetivos}

O principal objetivo do estudo foi determinar a freqüência da mutação do alelo G20210A da protrombina, por meio do método molecular da reação em cadeia da polimerase (PCR), em indivíduos sob investigação de trombofilia.

\section{Material e método}

O estudo do tipo série de casos (retrospectivo e prospectivo) foi realizado no Laboratório de Biologia Molecular da Fundação de Hematologia e Hemoterapia de Pernambuco (HEMOPE/PE), no período de março de 2001 a dezembro de 2005. As amostras de sangue periférico foram coletadas de indivíduos de ambos os sexos, independente da idade, após consentimento livre e esclarecido, sendo excluídos os familiares dos casos-índice.

O sangue foi coletado em tubo estéril, tipo Vacutainer, contendo ácido etilenodiaminotetracético (EDTA) como anticoagulante. O DNA genômico foi extraído mediante técnicas convencionais utilizando-se kits comerciais (Gentra Systems, Bio-Rad, EZ-DNA). A detecção das mutações foi realizada com auxílio do método molecular enzima de restrição/reação em cadeia da polimerase (RE/PCR), utilizando-se primers e enzima de restrição específicos. Para a amplificação foi preparado um mix contendo água Milli Q tratada com DEPC 0,01 \% (dietilpirocarbonato); tampão PCR 10x (Tris-HCl, 200 mM), pH 8,4; KCl, 500 mM (Invitrogen); $\mathrm{MgCl}_{2}, 50 \mathrm{mM}$ (Invitrogen); deoxinucleotídeos trifosfatos (dNTPs) 1,25 mM; um par de primers específicos para a mutação na concentração de $2,5 \mathrm{mM}$; Taq DNA polimerase recombinante $500 \mathrm{U}, 5 \mathrm{U} / \mu \mathrm{l}$ (Invitrogen), dimetilsulfóxido (DMSO) a 10 \% e o DNA genômico de cada indivíduo.

\section{Detecção da variante da protrombina G20210A}

A análise foi realizada por meio da amplificação por PCR segundo o método de SAIKI et al. ${ }^{(16)}$ de um fragmento da região 3'-UTR da protrombina. A reação envolveu 35 ciclos de amplificação com temperaturas de $94^{\circ} \mathrm{C}, 1 \mathrm{~min}$; $53^{\circ} \mathrm{C}, 1 \mathrm{~min}$; e $72^{\circ} \mathrm{C}, 1 \mathrm{~min}$, em termociclador (Bio-Rad ou Perkin Elmer). Para tal utilizou-se os primers PTCR1: 5'TCTAGAAACAGTTGCCTGGC- 3' e PTCR2: 5' - ATAGCACTGGGAGCATTGAAGC - 3' (Gibco BRL, EUA) de tal forma que a alteração genética na posição 20210 origina novo sítio de restrição para a enzima Hind III (Gibco BRL, EUA) após incubação a $37^{\circ} \mathrm{C}$ overnight(13).

Para a digestão do DNA foi utilizada alíquota de $8 \mu \mathrm{l}$ da amostra amplificada e $8 \mu \mathrm{l}$ de tampão REACT 2 10x (Gibco BRL); $\mathrm{NaCl} 50$ mM; Tris-HCl 10 mM; $\mathrm{MgCl}_{2} 10$ mM; 
ditiotreitol (DTT) pH 7,9 $1 \mathrm{mM}$, contendo $0,2 \mu \mathrm{l}$ de Hind III (Gibco BRL) na concentração de $1 \mathrm{U} / \mathrm{ml}$. O produto digerido foi separado por eletroforese e analisado em gel de agarose a $2 \%$, marcado com brometo de etídio e visualizado em transiluminador (Vilber Lourmat, Torcy, França) à luz ultravioleta.

A interpretação dos resultados foi realizada após fotodocumentação digital (Vilber Lourmat, Torcy, França) e análise das bandas e marcadores. Depois da digestão enzimática, o alelo normal apresenta fragmento único de $345 \mathrm{pb}$, enquanto o alelo mutado origina novo sítio de restrição, resultando na produção de fragmentos de $322 \mathrm{e}$ $23 \mathrm{pb}$ para homozigotos e fragmentos de 345,322 e 23 pb para heterozigotos.

\section{Análise estatística}

Para a criação do banco de dados e análise estatística, utilizou-se o programa Epi-Info 6.04 da Organização Mundial da Saúde (OMS). Como recurso estatístico descritivo foram utilizadas tabelas, e como medida de tendência central, a mediana. Os resultados foram expressos em valores absolutos e relativos. Como recurso inferencial, foi utilizado o teste do qui-quadrado $\left(\chi^{2}\right)$, com nível de significância de $5 \%$.

\section{Resultados}

Dos 285 indivíduos analisados para a PTCR, 17 (6\%) foram positivos, sendo todos heterozigotos. Do total de casos positivos, $3(17,6 \%)$ apresentavam história familiar de trombose.

A relação feminino vs. masculino obtida foi de 2 para 1, respectivamente, 193 e 92 indivíduos. Dos indivíduos heterozigotos, $10(58,8 \%)$ eram do sexo feminino e 7 $(41,2 \%)$ do masculino, sem diferença significante quanto ao gênero nos indivíduos com a mutação.

A mediana das idades foi 34 anos, com extremos de 1 e 92. A mediana das idades dos indivíduos positivos para PTCR foi 34 anos, com extremos de 7 e 65 . Não houve diferença estatística entre a mediana das idades dos grupos de indivíduos com ou sem a mutação. Também não houve diferença significativa entre os indivíduos positivos para a mutação da PTCR, em relação a idade ser superior ou inferior a 45 anos (Tabela).

\section{Discussão e conclusões}

O estudo mostrou freqüência de $6 \%$ para a mutação da protrombina. Esses dados são semelhantes à literatura cientifica para indivíduos com trombembolismo venoso ${ }^{(1,4)}$.

Em conformidade com dados publicados ${ }^{(5,17)}$, não houve diferença na análise quanto ao sexo e presença do alelo G20210A da protrombina.

A presença da PTCR pode ter sido determinante para o surgimento dos quadros trombóticos em determinado momento da vida dos pacientes sob investigação ${ }^{(5,10)}$. A baixa mediana de idade do grupo estudado sugere que outras causas genéticas de trombofilia devam ser investigadas, pois a maioria dos trabalhos associa a presença de fator de risco genético a eventos trombóticos em indivíduos com idade $<45$ anos $^{(5,17)}$.

\section{Agradecimentos}

Os autores agradecem à Fundação de Amparo a Ciência e Tecnologia do Estado de Pernambuco (FACEPE) pelo apoio financeiro.

Frequiência quanto à faixa etária em indivíduos encaminhados ao Laboratório de Biologia Molecular da Tabela HEMOPE para detecção da mutação da PTCR no período de março de 2001 a dezembro de 2005

$\begin{array}{lc} & \text { Faixa etária (anos) } \\ & \text { No de indivíduos } \\ \leq 45 & 228 \\ >45 & 57 \\ \text { Total } & 285\end{array}$

Protrombina mutante

HEMOPE/PE: Fundação de Hematologia e Hemoterapia de Pernambuco; PTCR: protrombina G20210A. 


\section{Referências}

1. ARRUDA, V. R. et al. Prevalence of the prothrombin gene variant (nt20210A) in venous thrombosis and arterial disease. Thromb Haemost, v. 78, n. 6, p. 1430-3, 1997.

2. BAUER, K. A.; ROSendAAL, F. R.; HeIT, J. A. Hipercoagulability: too many tests, too much conflicting data. Hematology, p. 353-68, 2002.

3. BERTINA, R. M. Genetic approach to thrombophilia. Thromb Haemost, v. 86, n. 1, p. 92-103, 2001.

4. DE STEFANO, V. et al. Screening for inherited thrombophilia: indications and therapeutic implications. Haematologica, v. 87, n. 10, p. 1095-108, 2002.

5. DE STEFANO, V. et al. Different circumstances of the first venous thromboembolism among younger or older heterozygous carriers of the G20210A polymorphism in the prothrombin gene. Haematologica, v. 88, n. 1, p. 61-6, 2003.

6. DUQUE, F. L. V.; MELLO, N. A. Trombogênese-trombofilia. J Vasc Bras, v. 2, n. 2, p. 105-18, 2003.

7. FRANCO, R. F. et al. Identification of polymorphisms in the 5'untranslated region of the tafi gene: relationship with plasma tafi levels and risk of venous thrombosis. Haematologica, v. 5, n. 86, p. 510-7, 2001.

8. LANE, D. A.; GRANT, P. J. Role of hemostatic gene polymorphisms in venous and arterial thrombotic disease. Blood, v. 95, n. 5, p. 1517-32, 2000.

9. LENS, D. et al. Diagnóstico molecular de factores protrombóticos: primeiros casos de factor $\mathrm{V}$ Leiden y protrombina G20210A en Uruguay. Rev Med Uruguay, v. 16, n. 1, p. 39-44, 2000.

10. MANNUCCI, P. M. The measurement of multifactorial thrombophilia. Thromb Haemost, v. 88, p. 1-2, 2002.
11. MATEO, J. et al. Increased risk of venous thrombosis in carriers of natural anticoagulant deficiencies: results of the family studies of the Spanish Multicenter Study on Thrombophilia (EMET study). Blood Coagul Fibrinolysis, v. 9, n. 1, p. 71-7, 1998.

12. NOWAK-GÖTTL, U. et al. Risk of recurrent venous thrombosis in children with combined prothrombotic risk factors. Blood, v. 97, n. 4, p. 858-62, 2001.

13. POORT, S. R. et al. A common genetic variation in the 3' untranslated region of the prothrombin gene is associated with elevated prothrombin levels and a increase in venous thrombosis. Blood, v. 88, n. 10, p. 3698-703, 1996.

14. REVEL-VILK, S.; MASSICOTTE, P. Thromboembolic diseases of childhood. Blood Rev, v. 17, p. 1-6, 2003.

15. ROSENDAAL, F. R. Venous thrombosis: a multicausal disease. Lancet North Am Ed, v. 353, p. 1167-73, 1999.

16. SAIKI, R. K. et al. Primer-directed enzymatic amplification of DNA with a thermostable DNA polymerase. Science, v. 239, n. 4839, p. 487-91, 1988.

17. SELIGSOHN, U.; LUBETSKY, A. Genetic susceptibility to venous thrombosis. N Engl J Med Overseas Ed, v. 344, n. 16, p. 1222-31, 2001.

18. ZAGO, M. A.; SILVA JR., W. A.; FRANCO, R. R. Hemoglobinopathies and other hereditary hematological diseases in the Brazilian population. Cienc Cult, v. 51, n. 3/4, p. 226-34, 1999.

19. ZIVELIN, A. et al. A Single genetic origin for the common prothrombotic G20210A polymorphism in the prothrombin gene. Blood, v. 92, n. 4, p. 1119-24, 1998. 